\title{
Ações Cooperativas para Prevenção e Combate a Incêndios Florestais em Área Protegida Urbana na Cidade do Rio de Janeiro
}

\author{
Izar Araujo Aximoff ${ }^{1}$, Luciano Araujo Menna Barreto ${ }^{1} \&$ Bruno Coutinho Kurtz $^{2}$
}

Recebido em 09/10/2019 - Aceito em 27/03/2020 1 Escola Nacional de Botânica Tropical, Programa de Pós-Graduação Profissional, Instituto de Pesquisas Jardim Botânico do Rio de Janeiro,
Rua Pacheco Leão 2040, Rio de Janeiro/RJ, Brasil. CEP: 22.460-036. <izar.aximoff@gmail.com, lucmenna@gmail.com>.
2 Instituto de Pesquisas Jardim Botânico do Rio de Janeiro, Rua Pacheco Leão 915, Rio de Janeiro/RJ, Brasil. CEP: 22.460-030.
<brunockurtz@gmail.com>.

\begin{abstract}
RESUMO - Incêndios florestais antrópicos são uma das maiores ameaças à conservação da biodiversidade, e ações efetivas de prevenção e combate devem ser prioritárias em áreas protegidas. O objetivo deste estudo foi traçar o perfil dos incêndios florestais e identificar as ações de prevenção e combate no Parque Estadual do Grajaú (PEG), na cidade do Rio de Janeiro. Os dados utilizados compreendem o período entre 2009 e 2017, e foram obtidos junto à gerência do PEG e, também, coletados in loco. Nesse período, foram registrados 22 incêndios no interior e na zona de amortecimento do Parque, com a maior parte dessas ocorrências (40,9\%) no ano de 2012, período anterior ao estabelecimento das cooperações técnicas e do voluntariado. O PEG conta com poucos recursos humanos, materiais e financeiros, mas as ações de prevenção e combate aos incêndios florestais, baseadas no estabelecimento de cooperação/parcerias e voluntariado, vêm colaborando para diminuir esse déficit. Observou-se uma tendência de diminuição das ocorrências de fogo e de sua extensão entre os períodos de 2009 a 2012 e 2013 a 2017, sendo essa diminuição estatisticamente significativa para a área queimada dentro do PEG. Os resultados revelam a importância dessas iniciativas para a gestão de uma área protegida e, principalmente, para as ações de prevenção $e$ combate a incêndios florestais em um cenário de déficit de recursos. Considera-se que esse exemplo pode ser replicado em outras áreas protegidas, tendo cada vez mais o envolvimento direto da sociedade na proteção da biodiversidade.
\end{abstract}

Palavras-chave: Incêndios antrópicos; Parque Estadual do Grajaú; unidade de conservação; voluntariado; zona de amortecimento.

\section{Cooperative Actions for the Prevention and Fighting of Forest Fires in an Urban Protected Area in the City of Rio de Janeiro}

\begin{abstract}
Anthropic fires are considered one of the greatest threats to biodiversity conservation. Effective prevention and action to combat fires should be a priority in protected areas. The objective of this study was to identify forest fire prevention and the strategies in place to combat fires in the Grajaú State Park (GSP). Data were collected from GSP management and additional information was obtained on site for the period 2009-2017. During the span of the study, 22 fires were registered in the Park interior and buffer zone. Most of these fires (40.9\%) occurred in 2012, prior to the initiation of technical cooperation and volunteer participation. Although there are few human, material and financial resources available to the Park, forest fire prevention and control are based on the establishment of cooperation/partnerships and volunteer participation, which have been helpful in reducing this deficit by promoting a decrease in fire spread inside the Park. The results reveal the importance of these initiatives for the management of a protected area and specifically for forest fire prevention and control in a resource deficient scenario. Conclusively, this example can be replicated in other protected areas by increasing direct involvement of society in the protection of biodiversity.
\end{abstract}

Keywords: Anthropic fires; buffer zone; Grajaú State Park; protected area; volunteer work. 


\title{
Acciones de Cooperación para la Prevención y Lucha contra Incendios Forestales en un Área Urbana Protegida en la Ciudad de Río de Janeiro
}

\begin{abstract}
RESUMEN - Los incendios antrópicos son considerados una de las mayores amenazas para la conservación de la biodiversidad. La prevención efectiva y las acciones de combate deben ser una prioridad en las áreas protegidas. El objetivo de este estudio fue identificar las acciones de prevención y de combate de los incendios forestales en el Parque Estatal de Grajaú (PEG). Los datos utilizados en la encuesta fueron del período de 2009 a 2017, obteniéndose a partir de la administración de PEG y de la recopilación in situ. Durante el estudio, se registraron 22 incendios entre el interior del parque y la zona de amortiguamiento. La mayoría de estos casos (40,9\%) fueron en 2012, antes del establecimiento de la cooperación técnica y el voluntariado. Aunque el Parque tiene pocos recursos humanos, materiales y financieros, las acciones de prevención y combate de incendios forestales, basadas en el establecimiento de cooperación/asociaciones y voluntariado, han estado ayudando a reducir este déficit, promoviendo la reducción de la extensión de los incendios dentro del Parque. Los resultados revelan la importancia de estas iniciativas para el manejo de un área protegida y, especialmente, para la prevención y el control de incendios forestales en un escenario de déficit de recursos. Se considera que este ejemplo puede replicarse en otras áreas protegidas, involucrando cada vez más a la sociedad en la protección de la biodiversidad de manera directa.
\end{abstract}

Palabras clave: Incendios antrópicos; Parque Estatal de Grajaú; unidad de conservación; voluntariado; zona de amortiguamiento.

\section{Introdução}

Incêndios florestais causam prejuízos econômicos, sociais e ambientais todos os anos no mundo. O fogo é considerado uma das principais ameaças para a conservação da biodiversidade e dos processos ecológicos em todo o território brasileiro (Soares \& Santos 2002), incluindo áreas protegidas (Santos et al. 2006), como parques nacionais (Koproski et al. 2004, Medeiros \& Fiedler 2004, Fiedler et al. 2006a, Aximoff \& Rodrigues 2011, Aximoff et al. 2016a) e parques estaduais (Bonfim et al. 2003, Tebaldi et al. 2013, Torres et al. 2018). Quando se trata de áreas protegidas, os efeitos do fogo sobre a biota devem ser criteriosamente avaliados, principalmente com relação a espécies ameaçadas (Hessl \& Spackman 1995, Yates \& Ladd 2010, Aximoff 2011, Aximoff et al. 2016a,b, Ooi 2019).

O sucesso no controle aos incêndios florestais depende de recursos humanos, financeiros $e$ materiais (Fiedler et al. 2006b, Bontempo et al. 2011, ICMBio 2012, Lima et al. 2018). Entretanto, o investimento e o número de servidores, por hectare, em unidades de conservação (UCs) no Brasil é um dos mais baixos do mundo (Medeiros et al. 2011), o que acaba por fragilizar a gestão dessas áreas (ICMBio 2012). Um dos problemas gerados é a carência de documentos e informações históricas sistematizadas, além da deficiência de planejamento, principalmente nas esferas estadual e municipal, visando à prevenção e combate a incêndios (Aximoff 2011, Lima et al. 2018). Isso, por si só, dificulta ainda mais a elaboração de políticas adequadas para a quantificação $e$ distribuição dos recursos.

O conhecimento do perfil e do regime dos incêndios florestais em UCs, da logística associada ao seu combate, sua frequência e sazonalidade, dos agentes causadores e extensão das áreas queimadas é fundamental para se traçarem estratégias eficientes para o planejamento de ações de prevenção e combate (Soares \& Santos 2002, Aximoff \& Rodrigues 2011, Tebaldi et al. 2013). Além disso, a eficiência no combate aos incêndios florestais pode ser conceitualmente simplificada, como a minimização do tempo envolvido em operações de detecção dos incêndios, comunicação com a base, preparação e início das operações, deslocamento, implantação de recursos na área da ocorrência, equipamentos disponíveis, controle e extinção do fogo (Bontempo et al. 2011, ICMBio 2012, Lima et al. 2018). Assim, a gestão pública impõe um desafio diário a ser vencido pelos gestores das áreas protegidas, que é a maximização do uso dos recursos públicos colocados à disposição para as diversas ações necessárias à preservação da biodiversidade. 
O Rio de Janeiro foi o estado brasileiro que apresentou o segundo maior número de ocorrências de incêndios florestais em áreas protegidas entre os anos de 2008 e 2012 (Lima et al. 2018). Na cidade do Rio de Janeiro, está uma das maiores florestas urbanas do planeta, localizada sobre o Maciço da Tijuca, protegida pelo Parque Nacional da Tijuca (PNT) e pelo Parque Estadual do Grajaú (PEG). Nesse maciço, que está rodeado por milhões de pessoas, em um período de quase 25 anos foram contabilizadas mais de 800 ocorrências de incêndio (Matos et al. 2002, Carapiá 2006, Aximoff et al. 2016a). Muitas vezes, o uso irregular do fogo no entorno desses parques, seja para limpeza de terreno, queima de lixo ou mesmo por soltura de balóes, acaba por ocasionar incêndios, comprometendo áreas florestadas e também ambientes com afloramentos rochosos onde são encontradas diversas espécies ameaçadas de extinção (Aximoff et al. 2016a). Para piorar esse cenário, o PEG não possui brigadistas contratados e dispõe de poucos equipamentos de combate a incêndios florestais, obtidos por meio de doação.

Os objetivos deste estudo foram traçar o perfil dos incêndios florestais, descrever as parcerias implementadas e identificar as ações de prevenção e combate no Parque Estadual do Grajaú, entre 2009 e 2017. Adicionalmente, buscou-se avaliar se houve redução dos incêndios, a partir de 2013, ano da efetivação de parcerias com instituições público-privadas e do voluntariado.

\section{Material e Métodos}

\section{Área de estudo}

O Parque Estadual do Grajaú possui área de 55ha, distribuídos sobre a encosta leste do Maciço da Tijuca, entre 40 e 444m de altitude, na cidade do Rio de Janeiro, estado do Rio de Janeiro, sudeste do Brasil (Figura 1). Desde 2007, é administrado pela Prefeitura do Rio de Janeiro, através do termo de sessão de uso (Rio de Janeiro 2007). A zona de amortecimento do PEG, com 433,43ha (Figura 2), foi definida em seu plano de manejo (IEF 2006).

Em seu interior, em meio a grandes blocos de afloramentos rochosos, existem fragmentos de floresta ombrófila densa submontana, em estágios secundário e inicial de regeneração, e também áreas degradadas, já queimadas (IEF 2006), e que hoje são ocupadas principalmente por duas espécies: o sabiá (Mimosa caesalpiniifolia Benth.; Fabaceae) e o capim colonião (Megathyrsus maximus (Jacq.) B.K. Simon \& S.W.L. Jacobs; Poaceae), sendo esta última considerada invasora e altamente inflamável, de difícil controle devido ao rápido crescimento $e$ à formação de touceiras extensas e densas, podendo chegar a $3 \mathrm{~m}$ de altura (Silva 1969, Carauta \& Oliveira 1982, PennaFirme et al. 2004, Aximoff et al. 2016a).

O PEG recebeu, a partir de 2008, alguns plantios oriundos de medidas compensatórias $e$ termos de ajustamento de conduta, os quais promoveram a conectividade com o Parque Nacional da Tijuca (Figuras 1 e 2), no corredor do vale do Urubu, junto à face norte do pico do Andaraí. Esses plantios foram acompanhados pela Secretaria Municipal de Meio Ambiente (SMAC) e, atualmente, vêm sendo mantidos pelo Mutirão de Reflorestamento da Prefeitura. Com cerca de 10 ha ( $20 \%$ da área da UC), os plantios foram realizados em local estratégico para a diminuição da incidência de incêndios, considerando seu papel como aceiro verde (Batista \& Biondi 2009, Kovalsyki et al. 2016).

Assim, o PEG contribui com mais de 50ha de floresta em diferentes estágios de sucessão na composição do mosaico de áreas protegidas na região metropolitana da cidade do Rio de Janeiro, além de propiciar estabilidade hidrogeológica para as encostas escarpadas do leste do Maciço da Tijuca (IEF 2006). De acordo com os dados do material depositado no herbário do Jardim Botânico do Rio de Janeiro e observações pessoais, existem no PEG oito espécies vegetais consideradas ameaçadas de extinção no Brasil (MMA 2014), e sete endêmicas e ameaçadas no estado do Rio de Janeiro, conforme Martinelli et al. (2018). Algumas delas (e.g., Alcantarea glaziouana (Leme) H. Rainer e Pitcairnia albiflos Herb.) são rupícolas e ocorrem sobre a Pedra do Andaraí, extenso afloramento rochoso com altitude de $444 \mathrm{~m}$.

Os limites do PEG são ocupados pelo Parque Nacional da Tijuca (a sudoeste), por comunidades do Morro do Encontro e Morro da Cutia (ao norte), Morro do Elefante (a oeste) e pelo bairro residencial do Grajaú (a leste). O uso público atual é, na maior parte, composto por escaladores, alunos de escolas e vizinhos do Parque, para atividades como piquenique, relaxamento, festas ao ar livre, aulas de yoga e educação ambiental 

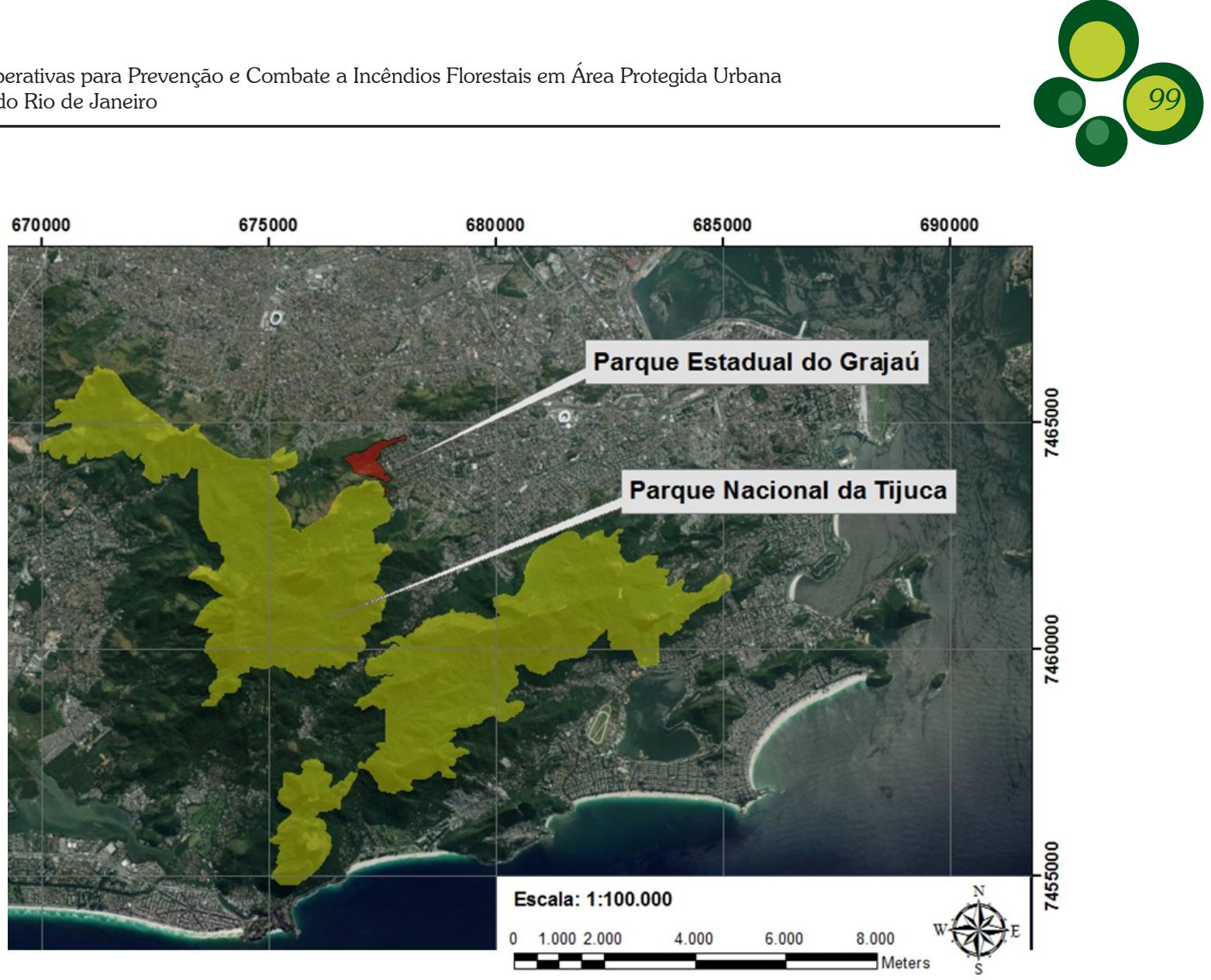

Figura 1 - Localização do Parque Estadual do Grajaú (em vermelho) e do Parque Nacional da Tijuca (em amarelo), na cidade do Rio de Janeiro, RJ.

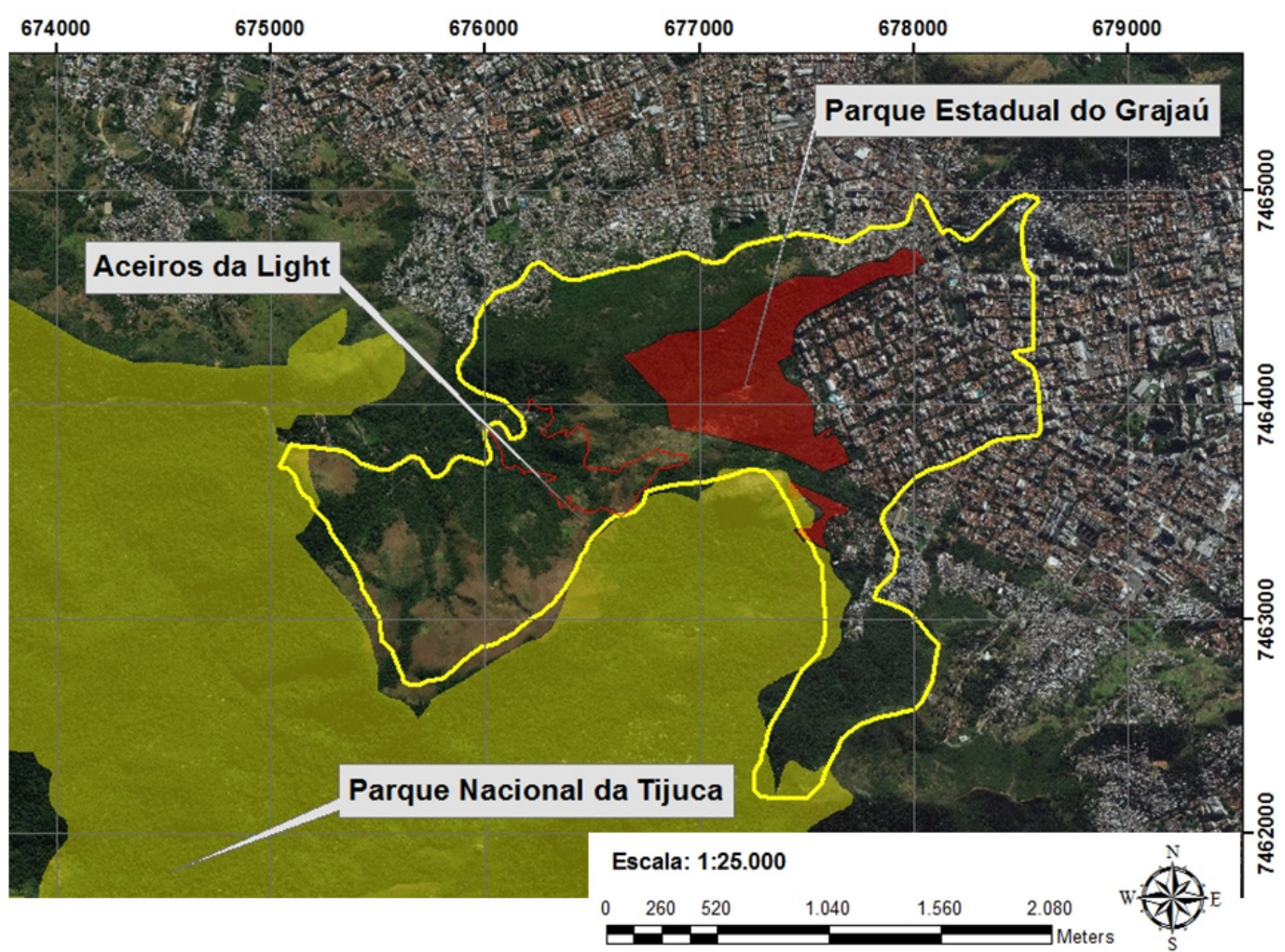

Figura 2 - Parque Estadual do Grajaú (em vermelho), sua zona de amortecimento (linha amarela) e aceiros da Light (linhas vermelhas), Rio de Janeiro, RJ. 
Tabela 1 - Precipitação (mm) no Parque Estadual do Grajaú, Rio de Janeiro, RJ, entre 2009 e 2017.

\begin{tabular}{|c|c|c|c|c|c|c|c|c|c|c|c|c|c|}
\hline $\mathbf{A n o}$ & Jan & Fev & Mar & Abr & Mai & Jun & Jul & Ago & Set & Out & Nov & Dez & $\begin{array}{c}\text { Total } \\
(\mathbf{m m})\end{array}$ \\
\hline $\mathbf{2 0 0 9}$ & 225 & 134 & 130 & 291 & 44,8 & 64,6 & 84 & 44 & 89,2 & 170 & 121 & 404 & 1801,6 \\
\hline $\mathbf{2 0 1 0}$ & 259 & 73,8 & 330 & 422 & 87,2 & 51,2 & 60 & 20 & 31,8 & 115 & 61,2 & 227 & 1738,6 \\
\hline $\mathbf{2 0 1 1}$ & 128 & 40,2 & 136 & 298 & 117 & 52 & 10 & 18 & 56,4 & 119 & 94,6 & 157 & 1224,8 \\
\hline $\mathbf{2 0 1 2}$ & 177 & 19 & 87,2 & 96,4 & 78,2 & 87,6 & 39 & 14 & 125 & 60,8 & 80,2 & 30 & 894,2 \\
\hline $\mathbf{2 0 1 3}$ & 383 & 100 & 284 & 74 & 95 & 31,6 & 86 & 25 & 66 & 78,4 & 122 & 261 & 1605,6 \\
\hline $\mathbf{2 0 1 4}$ & 76,6 & 50 & 98,6 & 137 & 20,6 & 69,4 & 52 & 43 & 46,4 & 18,4 & 33,8 & 77,8 & 723,6 \\
\hline $\mathbf{2 0 1 5}$ & 83,8 & 107 & 123 & 79,6 & 50 & 74,8 & 4,6 & 12 & 79,8 & 29,8 & 133 & 66,4 & 843,6 \\
\hline $\mathbf{2 0 1 6}$ & 186 & 167 & 185 & 9 & 43,8 & 65,8 & 8,4 & 68 & 44,8 & 37,6 & 134 & 158 & 1105,8 \\
\hline $\mathbf{2 0 1 7}$ & 133 & 20 & 103 & 166 & 32,8 & 185 & 28 & 53 & 9,2 & 36,4 & 80 & 81,4 & 928,2 \\
\hline
\end{tabular}

(Fonte: Alerta Rio)

(M. Carazza, comunicação pessoal). A presença de algumas comunidades de baixa renda no seu entorno impõe grande pressão, devido ao descarte inapropriado e à posterior queima de lixo, além do uso do espaço por grupos de criminosos que estabelecem regras de utilização da área com amplo uso de violência.

O clima no PEG, bem como em toda a região metropolitana do Rio de Janeiro, se enquadra como Aw (tropical savânico), segundo classificação de Köeppen, com temperatura média do mês mais frio maior que $18^{\circ} \mathrm{C} e$ precipitação do mês mais seco menor que $60 \mathrm{~mm}$. O período de menor pluviosidade vai de abril a setembro, durante as estações do outono e inverno, e o de maior pluviosidade inicia-se em outubro e estende-se até março, durante a primavera e verão (Tabela 1 ).

\section{Levantamento e análise dos dados sobre incêndios florestais}

As informações relacionadas aos incêndios florestais no PEG foram obtidas por meio dos Registros de Ocorrência de Incêndios (ROI), produzidos para os incêndios que atingiram o interior do Parque, e também por anotações das ocorrências na zona de amortecimento. Tais procedimentos estão de acordo com as orientações do Plano de Ação para Prevenção e Combate a Incêndios Florestais em Unidades de Conservação Federais (ICMBio 2012). Posteriormente, foram acrescentadas informações em relação a aspectos que compõem o combate a incêndios que não constavam dos ROIs, como localização, época de ocorrência, extensão da área atingida, forma de detecção, origem e causa do fogo, além de observações complementares sobre mobilização, deslocamento e duração. As classes de tamanho dos incêndios foram ordenadas de acordo com padrão adotado pelo Canadian Forest Service (Ramsey \& Higgins 1981): Classe I (<0,1ha), Classe II (0,1 a 4,0ha), Classe III (4,1 a 40,0ha), Classe IV (40,1 a 200,0ha) e Classe V (>200,0ha). As classes de duração do tempo (minutos) para o ataque aos incêndios foram ordenadas de acordo com padrão adotado por Lima \& Soares (1992): Classe I (até 30min), Classe II (31 a 60min), Classe III (61 a 120min), Classe IV (121 a 480min) e Classe V (acima de 480min).

Para avaliar se houve redução no número de incêndios florestais, bem como na área queimada dentro do PEG e em sua zona de amortecimento, entre o período anterior ao estabelecimento das parcerias com instituições público-privadas $e$ voluntariado (2009-2012) e aquele a partir dessas iniciativas (2013-2017), foi aplicado o teste não paramétrico de Mann-Whitney (Zar 1996). 


\section{Resultados e Discussão}

\section{Implementação das parcerias}

Embora o PEG conte com poucos recursos, o estabelecimento de parcerias e o trabalho voluntário vêm colaborando para diminuir esse déficit. Iniciada em 2009, a parceria com o Instituto Iguaçu de Preservação e Pesquisa trouxe os primeiros voluntários da atual gestão. Em 2012, iniciaram-se as parcerias com instituições público-privadas $\left(11^{\circ}\right.$ Grupamento de Bombeiro Militar, $1^{\circ}$ Grupamento de Socorro Florestal e Meio Ambiente, Defesa Civil Municipal, Cia Light, Grajaú Country Clube e Associação de Moradores do Grajaú), efetivadas no final daquele ano. Essas parcerias foram articuladas como resposta ao grande número de focos de incêndios em 2012. Inicialmente foram estabelecidos os canais de comunicação por meio de reuniões, onde se identificaram os recursos humanos $e$ materiais disponíveis e, por fim, foram produzidos em conjunto os protocolos de acionamento $e$ combate. O território do PEG é atravessado por linhas de transmissão de energia da Cia Light $e$ há um acordo de cooperação entre a Prefeitura e essa empresa, referente, sobretudo, às atividades de prevenção de incêndios florestais, tais como a manutenção de acessos e aceiros, já que a própria faixa da linha de transmissão funcionava como corredor de propagação de incêndios.

A partir de 2014, o voluntariado no PEG passou a ser promovido pelo Instituto Naturalis, através de seu programa implementado em unidades de conservação, em que voluntários vêm desenvolvendo atividades de apoio nas seguintes linhas de ação: manejo para conservação da flora nativa; pesquisa e monitoramento; gestão socioambiental; apoio ao setor de uso público intensivo; produção de mudas nativas da Mata Atlântica; estudos de consolidação territorial $e$ proteção ambiental. Além disso, o trabalho voluntário tem promovido avanços nas ações preventivas e de combate aos incêndios, por meio da arrecadação de doações de ferramentas $e$ equipamentos, articulações com parceiros para manutenção dos aceiros, atividades educativas e de sensibilização, desenvolvimento de treinamentos para brigadistas e cursos. Os voluntários do Instituto Naturalis, por exemplo, promoveram palestras para a academia militar dos bombeiros e curso de Prevenção e Combate a Incêndios Florestais para a Prefeitura Municipal do
Rio de Janeiro, além de participar dos cursos para brigadistas no Parque Nacional da Tijuca.

$\mathrm{O}$ deficit de pessoal, equipamentos $e$ infraestrutura faz com que a gestão de unidades de conservação seja precária (Fiedler et al. 2006b, Tebaldi et al. 2013). No entanto, mesmo o investimento na contratação de brigadistas $e$ aquisição de material de combate pode não ser suficiente para a redução das áreas queimadas, como ocorreu recentemente nas áreas protegidas do estado do Espírito Santo (Tebaldi et al. 2013). No PEG, por exemplo, os recursos humanos e materiais disponibilizados entre 2009 e 2017 foram escassos, e a maior parte dos recursos da UC é oriunda de doações, parcerias e do trabalho voluntário (Tabela 2). Contudo, alguns equipamentos operacionais básicos para combate e prevenção, como bomba-costal rígida, rádio comunicador, motosserra e até telefone fixo, não existem na UC e ainda não foram obtidos por meio das parcerias.

\section{Medidas preventivas}

Uma das técnicas mais utilizadas para impedir a propagação do fogo ou diminuir sua intensidade é a redução ou supressão da quantidade de material combustível existente, principalmente sobre o solo, por meio da construção de aceiros (Soares \& Batista 2007). No interior do PEG, os aceiros foram construídos de maneira semimecanizada, com uso de ferramentas manuais, como enxada, foice, facão, rastelo, motosserra, machado e roçadeira, já que o relevo acidentado e a presença de muitos blocos de pedra impedem o uso de tratores $e$ outras máquinas pesadas. Esse é o método com menor custo operacional para o cenário de hoje. $\mathrm{Na}$ ocasião da construção, foram consideradas recomendações básicas, como evitar áreas com solo frágil e com declividade, dando preferência a fundo de vale ou a logo após o topo de morro, além de utilizar barreiras naturais, como corpos hídricos, rochas, florestas densas ou mesmo estradas e outros aceiros já existentes (Ribeiro et al. 2006). A possibilidade de uso de queima prescrita ou aceiro negro foi apresentada ao gestor do PEG, que, de imediato, não autorizou o uso do fogo no interior do Parque.

Os três aceiros abertos em 2011, com $1.511 \mathrm{~m}$ de extensão e entre 4 e $6 \mathrm{~m}$ de largura, 
Tabela 2 - Recursos humanos e equipamentos relacionados às ações de prevenção e combate a incêndios florestais no Parque Estadual do Grajaú, Rio de Janeiro, RJ, entre os anos de 2009 e 2017.

\begin{tabular}{|c|c|c|c|}
\hline Categoria & Descrição & PEG & $\begin{array}{l}\text { Cooperação e } \\
\text { voluntariado }\end{array}$ \\
\hline \multirow{8}{*}{$\begin{array}{l}\text { Equipamento de proteção } \\
\text { individual }\end{array}$} & Uniforme & 0 & 10 \\
\hline & Capacete & 0 & 10 \\
\hline & Luva & 0 & 10 \\
\hline & Máscara & 0 & 10 \\
\hline & Bota & 0 & 10 \\
\hline & Óculos de segurança & 0 & 10 \\
\hline & Cantil & 0 & 10 \\
\hline & Kit de primeiros socorros & 0 & 10 \\
\hline \multirow{5}{*}{ Ferramentas } & Abafador* & 0 & 8 \\
\hline & Vassoura de bruxa & 2 & 0 \\
\hline & Mochila-costal flexível & 2 & 0 \\
\hline & Enxada & 2 & 0 \\
\hline & Rastelo & 1 & 0 \\
\hline \multirow{7}{*}{ Recursos humanos } & Administrador & 1 & 0 \\
\hline & Técnico administrativo & 1 & 0 \\
\hline & Pesquisador/perito & 0 & 2 \\
\hline & Guarda municipal & 1 & 0 \\
\hline & Vigia noturno desarmado & 1 & 0 \\
\hline & Brigadistas/voluntários & 0 & 20 \\
\hline & $\begin{array}{c}\text { Funcionário da Companhia Municipal de } \\
\text { Limpeza Urbana (Comlurb) }\end{array}$ & 2 & 0 \\
\hline \multirow{11}{*}{$\begin{array}{l}\text { Equipamentos operacionais } \\
\text { (externos e internos) }\end{array}$} & GPS & 0 & 1 \\
\hline & Câmera fotográfica & 0 & 2 \\
\hline & Celular & 0 & 1 \\
\hline & Roçadeira & 0 & 2 \\
\hline & Caixa de ferramentas & 1 & 0 \\
\hline & Veículo passeio & 0 & 2 \\
\hline & Veículo $4 \times 4$ & 0 & 2 \\
\hline & Retroescavadeira & 0 & 1 \\
\hline & Computador & 0 & 1 \\
\hline & Internet & 0 & 1 \\
\hline & Estação meteorológica & 0 & 1 \\
\hline
\end{tabular}

* Doação para o PEG. 
impediram que incêndios no interior do PEG (jul/2012, set/2012, jun/2016 e nov/2017) causassem danos aos plantios realizados naquele ano. Na zona de amortecimento do PEG, existe outro aceiro, localizado no Morro do Elefante, com $2.830 \mathrm{~m}$ de extensão e $4 \mathrm{~m}$ de largura. Esse aceiro foi feito em uma antiga estrada utilizada para manutenção das linhas e torres de transmissão de energia que cortam o Parque. Observou-se, in loco, que esse aceiro conteve o avanço dos incêndios naquela localidade, situada fora dos limites do PEG. A Figura 3 ilustra os efeitos do fogo $e$ as ações de prevenção e combate aplicadas no PEG a partir do final de 2012.
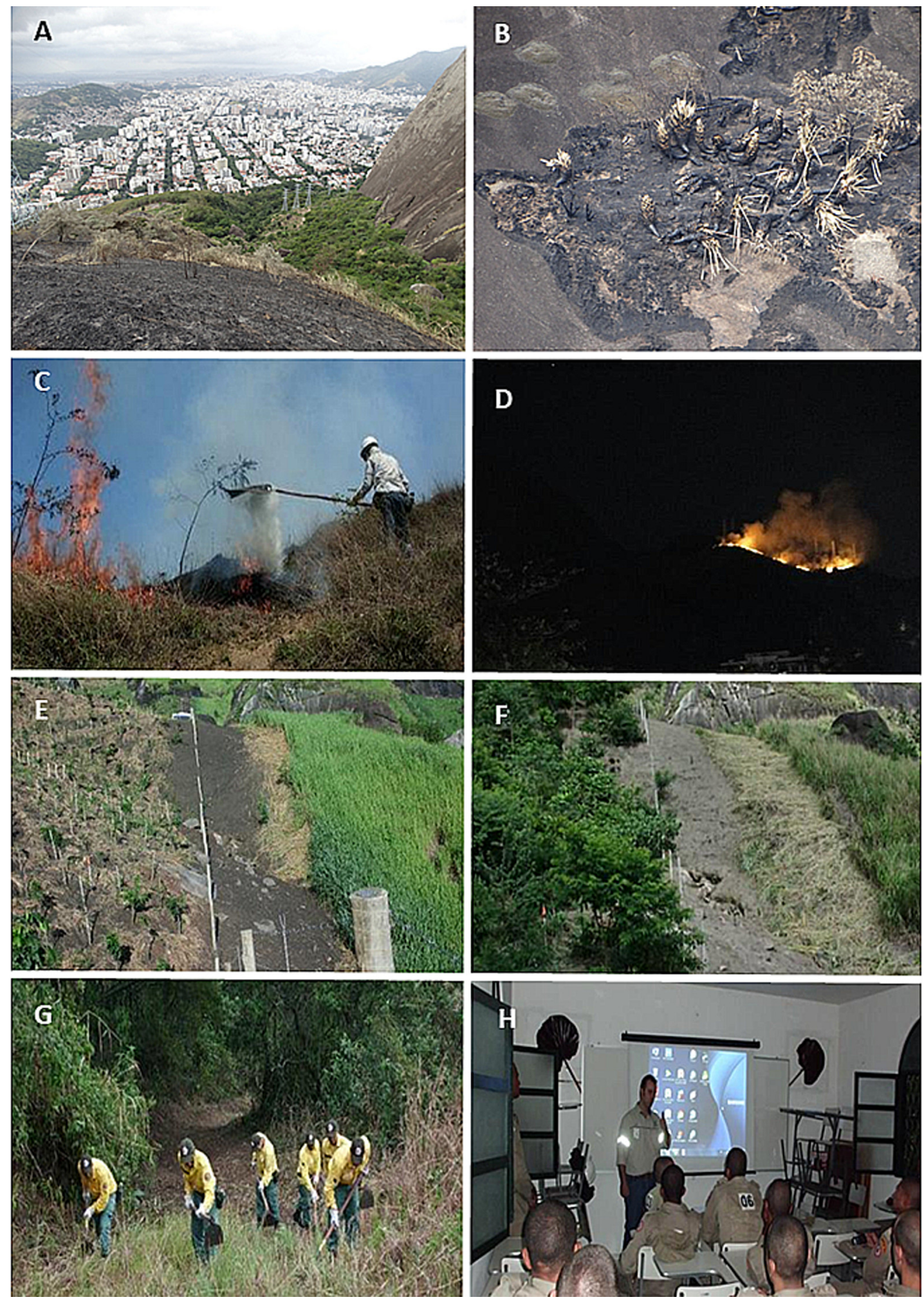

Figura 3 - Incêndios e ações de prevenção e combate no Parque Estadual do Grajaú, Rio de Janeiro, RJ. A) Área queimada em 2015; B) Vegetação rupícola queimada; C) Combate a incêndio por voluntário; D) Visão noturna de incêndio florestal; E) Aceiro e cercamento das mudas no plantio (2011); F) Aceiro e desenvolvimento das mudas (2015); G) Brigadistas do PREVFOGO IBAMA realizando abertura de aceiro; H) Treinamento para bombeiros, brigadistas e voluntários. Fotos: L. Menna Barreto. 
Os aceiros também servem como rota de acesso para deslocamento rápido e seguro das equipes de brigadistas e bombeiros na região, facilitando o combate. Alguns aceiros foram contemplados com roçadas de $6 \mathrm{~m}$ de largura em suas faixas marginais, diminuindo a radiação de calor emanada dos incêndios sobre os combatentes e exemplares plantados nas linhas junto aos aceiros. A manutenção desses aceiros, realizada em média a cada três meses, demanda esforço conjunto por 40 dias de trabalho intenso. $\mathrm{O}$ aceiro localizado na zona de amortecimento é tratorável, ou seja, pode ser mantido com roçadeira acoplada a um trator. No PEG, a atividade de manutenção desse aceiro contou com apoio de uma retroescavadeira da prefeitura. A atividade de manutenção de aceiros é considerada de extrema importância na prevenção de incêndios florestais (Soares \& Batista 2007), visto que, em uma determinada ocasião, após forte ventania, algumas árvores foram derrubadas sobre o aceiro, deixando, assim, trechos vulneráveis à condução do fogo por uma semana. Apesar da importância, a atividade de manutenção não tem ocorrido de maneira constante nos últimos anos devido à falta de segurança.

Embora os aceiros tenham funcionado de maneira satisfatória em várias ocorrências de incêndios, sendo considerados pela SMAC como um projeto de sucesso, atualmente a utilização de outras técnicas de prevenção, que não necessitem de manutenção periódica em áreas sem segurança, está sendo avaliada. $\mathrm{O}$ aceiro verde, que causa pouco impacto por ser formado a partir do plantio de faixas com espécies de menor inflamabilidade (Batista \& Biondi 2009, Kovalsyki et al. 2016), pode ser uma boa opção.

\section{Incêndios florestais}

No período de 2009 a 2017, foram registrados 22 incêndios florestais no interior e na zona de amortecimento do Parque Estadual do Grajaú, com a maior parte dessas ocorrências no ano de 2012 ( $n=9 ; 40,9 \%$; Figura 4), período anterior ao estabelecimento das ações de prevenção e combate baseadas nas cooperações e no voluntariado. Esse foi um ano bastante seco, quando comparado ao período de 2009 a 2011 (Tabela 1). Nos anos de 2014, 2015 e 2017, também secos, o número de incêndios foi menor, o que pode ser atribuído, em parte, às ações de prevenção e combate.

Tendo em conta outras áreas protegidas na Floresta Atlântica, fica evidente o número elevado de ocorrências no PEG, considerando sua extensão de menos de 500ha, incluindo sua zona de amortecimento. No Parque Estadual da Serra do Brigadeiro (14.984ha), por exemplo, no estado de Minas Gerais, ocorreram 34 incêndios entre 2007 e 2015, e no Parque Estadual da Vila Velha (3.122ha), no Paraná, foram registrados 32 incêndios entre 2009 e 2013 (Torres et al. 2018). Já no Parque Nacional de Ilha Grande (78.875ha), também no Paraná, totalizaram-se 52 incêndios entre 1999 e 2003 (Koproski et al. 2004).

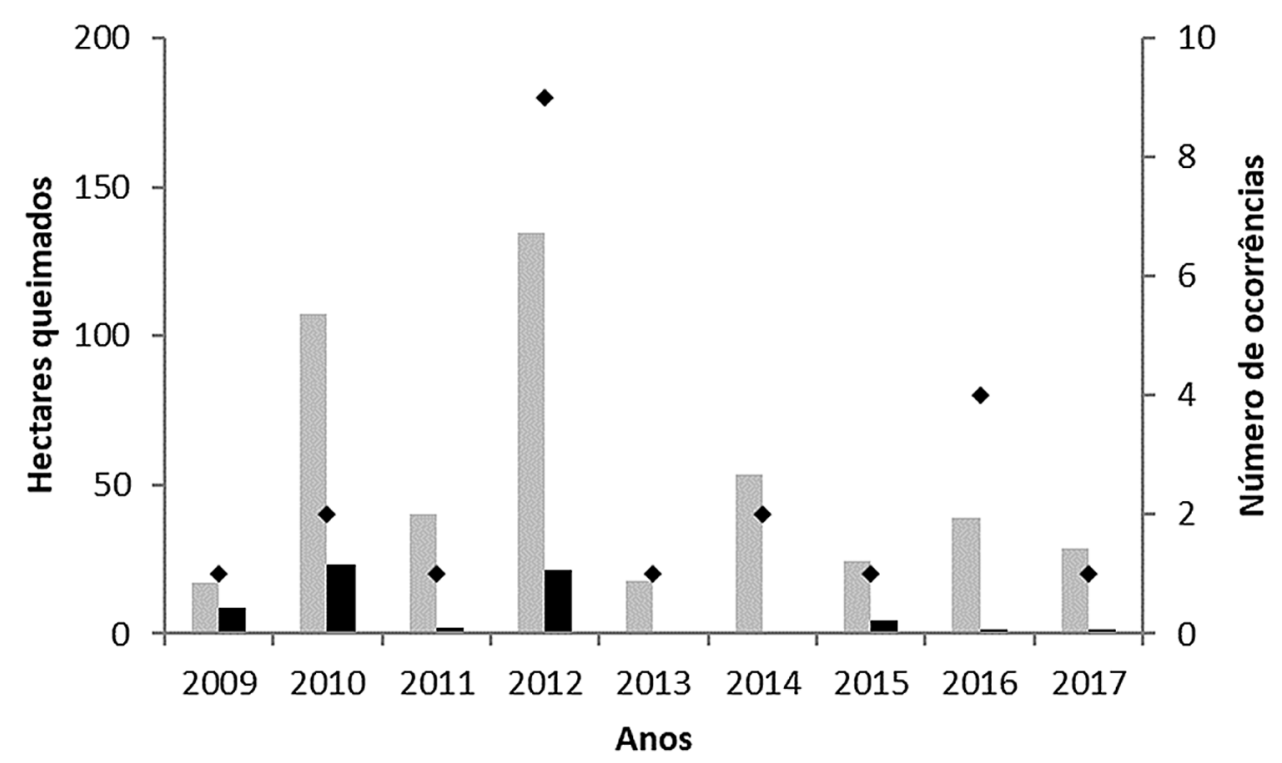

Figura 4 - Registros de incêndios florestais, por ano, no Parque Estadual do Grajaú, Rio de Janeiro, RJ. Pontos pretos = número de ocorrências; barras pretas e cinza $=$ hectares atingidos no interior $e$ na zona de amortecimento do Parque, respectivamente. 
O elevado número de incêndios ocorridos no PEG parece estar relacionado à sua localização em ambiente urbano. Outras áreas protegidas na região metropolitana do Rio de Janeiro, como o Parque Natural Municipal da Prainha, Monumento Natural dos Morros da Urca e Pão de Açúcar, Parque Estadual da Serra da Tiririca, Parque Estadual da Pedra Branca e Parque Nacional da Tijuca, dentre outras, sofrem com incêndios decorrentes de atividades ilegais relacionadas a ambientes mais urbanizados, como, por exemplo, soltura de balões, queima de lixo e práticas religiosas (Aximoff et al. 2016a).

Não foram obtidos registros de ocorrências de incêndios anteriores ao período estudado devido à não compilação dessas informações ou à perda desses dados. A ausência de informações parece ser um padrão que se repete para outras áreas protegidas na região metropolitana do Rio de Janeiro (Aximoff et al. 2016a). Ademais, apenas $41 \%$ dos ROIs de mais de 900 áreas protegidas federais no Brasil apresentaram informações básicas, como o tamanho da área queimada, tempo para $\mathrm{o}$ ataque (i.e., tempo de resposta para o primeiro combate) e tempo de combate (Lima et al. 2018). Com esses dados, planeja-se o controle de modo mais eficiente e até mesmo políticas mais adequadas para provimento de recursos; sem eles, subestimam-se ou superestimam-se os gastos relacionados à proteção do ambiente, colocando em risco a sobrevivência das florestas (Santos et al. 2006, Bontempo et al. 2011).

Em relação aos incêndios, a maior parte das ocorrências no PEG $(59,1 \%)$ foi enquadrada na Classe III (4,1 - 40,0ha) (Tabela 3), resultado similar ao encontrado em outras áreas protegidas brasileiras (Santos et al. 2006, Tebaldi et al. 2013, Torres et al. 2018). As Classes III e IV foram similares em hectares atingidos, com $49 \%$ do total para cada classe. Foram registradas quatro ocorrências que queimaram acima de 40ha (Classe IV), em 2010 e 2012. A eficiência de um sistema de combate a incêndios será melhor quanto maior for a proporção de incêndios com área queimada nas Classes I e II (Santos et al. 2006).

Após o estabelecimento das parcerias com instituições público-privadas e do voluntariado para promover ações de prevenção e combate, em 2013, observa-se uma tendência de diminuição na área queimada dentro do PEG e em sua zona de amortecimento. Entretanto, apenas a área queimada no interior do PEG foi significativamente menor no período de 2013 a 2017, em relação ao período de 2009 a 2012 (Tabela 4). Considerando que não houve diferença significativa no número de incêndios, a redução da área queimada dentro do PEG pode estar relacionada a uma resposta mais rápida de combate a partir das parcerias citadas.

Tabela 3 - Classes de tamanho dos incêndios florestais no Parque Estadual do Grajaú, Rio de Janeiro, RJ, entre 2009 e 2017.

\begin{tabular}{|c|c|c|c|c|c|}
\hline \multirow{2}{*}{ Classe } & \multirow{2}{*}{ ha } & \multicolumn{3}{|c|}{ Ocorrências } & \multicolumn{2}{c|}{ Área queimada } \\
\cline { 3 - 6 } & & $\mathbf{n}^{\circ}$ & $\%$ & ha & - \\
\hline I & $0-0,09$ & 0 & - & - & 1,8 \\
\hline II & $0,1-4,0$ & 5 & 22,7 & 25,22 & 49,0 \\
\hline III & $4,1-40,0$ & 13 & 59,1 & 257,35 & 49,3 \\
\hline IV & $40,1-200,0$ & 4 & 18,2 & - & - \\
\hline V & $>200$ & 0 & - & & \\
\hline
\end{tabular}

Tabela 4 - Comparação, pelo teste de Mann-Whitney, do número de incêndios, por ano, e da área queimada no interior e na zona de amortecimento (ZA) do Parque Estadual do Grajaú, Rio de Janeiro, RJ, entre os períodos de 2009-2012 e 2013-2017.

\begin{tabular}{|c|c|c|c|c|}
\hline Parâmetro & Média \pm desvio padrão 2009-2012 & Média \pm desvio padrão 2013-2017 & U & $\boldsymbol{p}$ \\
\hline Número de incêndios/ano & $3,3 \pm 3,9$ & $1,8 \pm 1,3$ & 8,5 & 0,71 \\
\hline Hectares queimados no PEG/ano & $13,9 \pm 10,3$ & $1,5 \pm 1,8$ & 1 & $0,03 *$ \\
\hline Hectares queimados na ZA/ano & $74,7 \pm 55,3$ & $32,7 \pm 14,2$ & 6 & 0,33 \\
\hline
\end{tabular}


O Morro do Elefante, na zona de amortecimento do PEG, foi o local com maior número de ocorrências $(68,1 \%)$ e maior extensão de áreas queimadas, com 289,7 ha (55,5\% do total). Esse morro possui diversas características que facilitam a ocorrência e propagação dos incêndios, como dominância do capim gordura (Melinis minutiflora P. Beauv.) e do capim sapê (Imperata brasiliensis Trin.), declividade acentuada e encostas voltadas para o norte, que recebem maior radiação solar. Esses fatores favorecem a diminuição do teor de umidade no solo e no combustível florestal, aumentando do risco de incêndios (Soares \& Batista 2007, Torres et al. 2018). No Maciço da Tijuca, as encostas voltadas para o norte apresentam quase duas vezes menos umidade e quase $100 \%$ das ocorrências de temperaturas máximas, quando comparadas com encostas voltadas ao sul (Oliveira et al. 1995). O número de ocorrências, bem como a intensidade, a velocidade de propagação e a extensão de um incêndio estão diretamente ligados à baixa umidade relativa $e$ à elevada temperatura, além da velocidade do vento (Soares \& Batista 2007, ICMBio 2012, Torres et al. 2018).

Metade dos incêndios ocorreu entre junho e agosto (Figura 5), sendo que cinco das oito ocorrências em que o combate durou mais de um dia foram justamente nesse período. Nessa época do ano, ocorre o menor volume de precipitação e, por outro lado, a maior frequência de soltura de balões e utilização de fogos de artifício, durante as festas de São João (Aximoff et al. 2016a), além da queima do capim para renovação de pastagem (Aximoff et al. 2016b). A maioria das ocorrências de incêndios florestais no Brasil se concentra no inverno e início de primavera, no período compreendido entre junho a outubro, que corresponde à estação mais seca do ano em quase todo o território nacional (Soares \& Santos 2002, Santos et al. 2006, Lima et al. 2018).

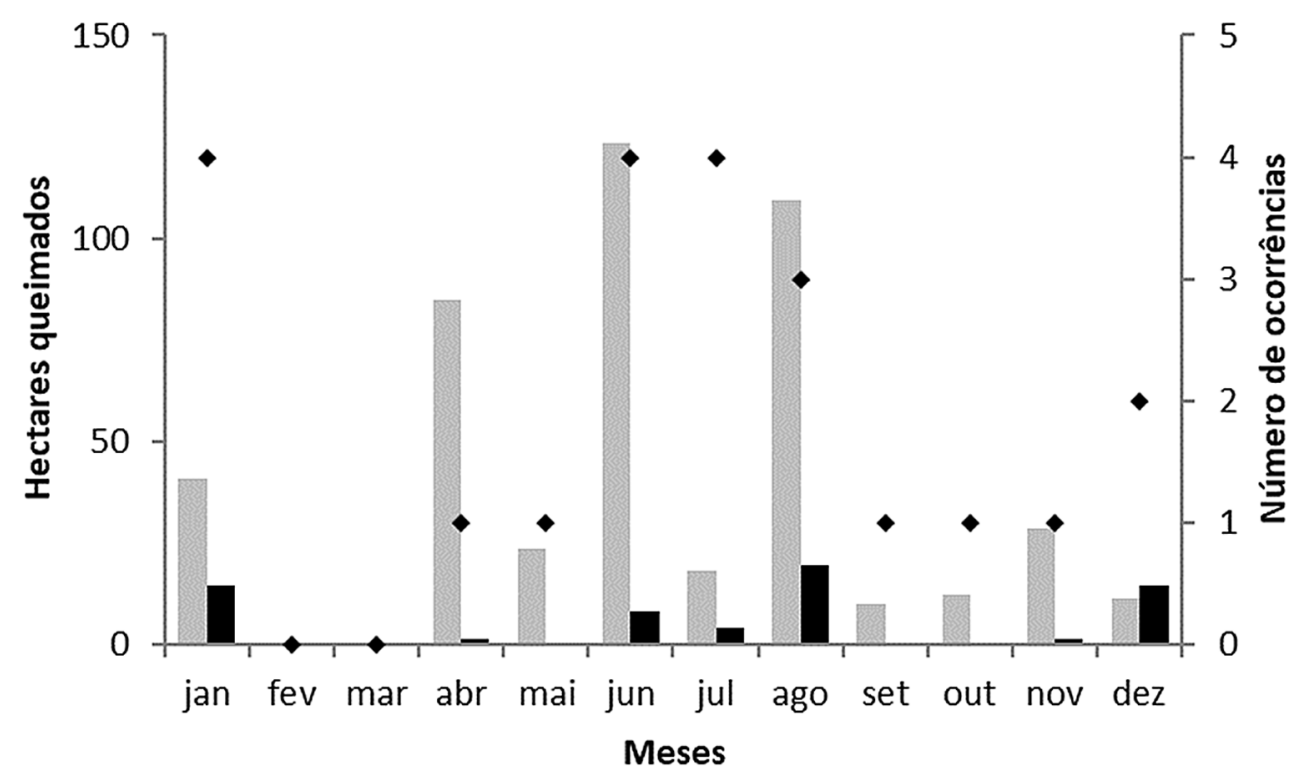

Figura 5 - Registros de incêndios florestais por mês, no período de 2009-2017, no Parque Estadual do Grajaú, Rio de Janeiro, RJ. Pontos pretos = número de ocorrências; barras pretas e cinza $=$ hectares atingidos no interior e na zona de amortecimento, respectivamente.

Todas as 22 ocorrências de incêndios registradas no PEG tiveram agentes causadores identificados, diferentemente de outros estudos em que a maior parte teve agentes causadores desconhecidos ou indeterminados, como consequência da precariedade do sistema de perícias (Aximoff 2011, Tebaldi et al. 2013). A maioria dos incêndios foi originada por incendiários (50\%), sendo a causa principal a soltura de balóes $(36,4 \%$ das ocorrências). A limpeza de terreno/queima de lixo foi a principal causa $(54,5 \%)$, tendo os moradores do entorno como o principal agente causador $(27,3 \%)$. Os resultados estão de acordo com a origem antrópica dos incêndios em outros parques na Floresta Atlântica no sudeste brasileiro (Tebaldi et al. 2013, Aximoff et al. 2016a). 


\section{Ações de combate}

Considerando todas as ocorrências de incêndios no PEG e sua zona de amortecimento, o tempo de ataque foi, geralmente, de menos de 30min (Classe I). Esse tempo foi maior apenas para algumas ocorrências (Classe III: de 61 a $120 \mathrm{~min}$ ), anteriores ao estabelecimento de cooperação institucional a partir do final de 2012. A facilidade de deslocamento promovida pelos aceiros e o curto espaço de tempo entre a detecção e mobilização da equipe de combate, decorrente da eficiência das articulações institucionais e bombeiros do $11^{\circ}$ Batalhão de Corpo de Bombeiros Militar do Estado do Rio de Janeiro, diminuíram o tempo de ataque. A questão crítica em sistemas de monitoramento de incêndios florestais é a resposta imediata, a fim de minimizar a escala da destruição (ICMBio 2012, Penman et al. 2013). Em estudo que avaliou ações de combate em 55 unidades de conservação federais brasileiras, o tempo médio para o ataque foi de 195min (Classe IV) para uma área queimada média de 613,61ha (Lima et al. 2018). Deve-se observar, entretanto, que muitas áreas protegidas federais possuem grande extensão, se comparadas ao PEG, e estão localizadas em regiões remotas.

A detecção de todos os incêndios foi realizada pela vigilância comunitária, sendo considerado como um resultado positivo do treinamento de alguns voluntários, indicados pelas associações de moradores e pelo chefe do PEG. Essa forma de monitoramento gerou despesas irrelevantes e agilizou o start do protocolo de resposta. Um sistema de detecção e comunicação eficiente faz com que os focos de incêndio sejam detectados mais rapidamente e, assim, o combate e o controle possam ser efetivados de forma mais imediata. A discussão sobre o tema fogo entre instituições públicas, privadas e a sociedade civil é de suma importância para o andamento das atividades de prevenção (Medeiros \& Fiedler 2004, ICMBio 2012). Contudo, existe necessidade de uma política pública municipal efetiva que fortaleça a capacidade de planejar, implementar e manejar apropriadamente as áreas protegidas em relação às ameaças, incluindo o próprio deficit de recursos e equipamentos.

Em relação às dificuldades encontradas $e$ aos desafios para o aprimoramento futuro do trabalho de prevenção e combate a incêndios florestais, destacamos que a dependência do
Corpo de Bombeiros do quartel local para o primeiro combate resultava em sobrecarga para eles, que atendem vários tipos de ocorrências no bairro. Além do mais, depois do atendimento ao trabalho de combate dos incêndios florestais, as equipes do Corpo de Bombeiros ficavam exaustas e, em alguns casos, ainda tinham que cumprir 48 horas de serviço de rescaldo. O desafio para o futuro é ter uma brigada que atenda ao PEG em suas demandas de prevenção e combate a incêndios florestais. Além disso, a avaliação por parte do gestor, em relação à utilização de queimas prescritas e/ou aceiros negros de pequenas proporções em áreas campestres de exóticas no interior e/ou na zona de amortecimento, pode, ao mesmo tempo, impedir a propagação de incêndios para o interior da UC e proteger as comunidades lindeiras da propagação de fogo da UC para suas moradias.

A diminuição da extensão da área queimada no interior do PEG revela a importância das cooperações institucionais e do voluntariado para as ações de prevenção e combate a incêndios florestais em um cenário de deficit de pessoal, de recursos financeiros e de equipamentos na área em questão. Espera-se que este exemplo possa ser replicado em outras áreas protegidas e que, cada vez mais, a sociedade se envolva diretamente na proteção da biodiversidade.

\section{Agradecimentos}

Os autores agradecem aos revisores anônimos, à editora Dra. Katia Torres e ao Gestor do PEG Marcio Carazza.

\section{Referências Bibliográficas}

Aximoff I. O que perdemos com a passagem do fogo pelos campos de altitude do estado do Rio de Janeiro? Biodiversidade Brasileira, 2: 180-200, 2011.

Aximoff I \& Rodrigues RC. Histórico dos incêndios florestais no Parque Nacional do Itatiaia. Ciência Florestal, 21(1): 83-92, 2011.

Aximoff IA, Fraga CN \& Bovini MG. Vegetação em afloramentos rochosos litorâneos perturbados por incêndios na região metropolitana fluminense, estado do Rio de Janeiro. Biodiversidade Brasileira, 2: 149-172, 2016a.

Aximoff I, Nunes-Freitas AF \& Braga JMA. Regeneração natural pós-fogo nos campos de altitude no Parque 
Nacional do Itatiaia, sudeste do Brasil. Oecologia Australis, 20(2): 200-218, 2016b.

Batista AC \& Biondi D. Avaliação da inflamabilidade de Ligustrum lucidum Aiton (Oleaceae) para uso potencial em cortinas de segurança na região sul do Brasil. Revista Brasileira de Ciências Agrárias, 4(4): 435-439, 2009.

Bonfim VR, Ribeiro GA, Silva E \& Braga GM. Diagnóstico do uso do fogo no entorno do Parque Estadual da Serra do Brigadeiro (PESB), MG. Revista Árvore, 27(1): 87-94, 2003.

Bontempo GC, Lima GS, Ribeiro GA, Doula SM \& Jacovine LAG. Registro de Ocorrência de Incêndio (ROI): evolução, desafios e recomendações. Biodiversidade Brasileira, 2: 247-263, 2011.

Carapiá VR. 2006. Predição do índice de risco de incêndios e modelagem computacional do comportamento do avanço da frente do fogo no Parque Nacional da Floresta da Tijuca. Tese (Doutorado em Engenharia Civil). Universidade Federal do Rio de Janeiro. 177p.

Carauta JPP \& Oliveira RR. 1982. Fitogeografia das encostas do Pão de Açúcar, p. 9-31. In: Flora: alguns estudos - II (Cadernos FEEMA, série trabalhos técnicos 2/82). Fundação Estadual de Engenharia do Meio Ambiente.

Fiedler NC, Merlo DA \& Medeiros MB. Ocorrência de incêndios florestais no Parque Nacional da Chapada dos Veadeiros, Goiás. Ciência Florestal, 16(2): 153-161, 2006a.

Fiedler NC, Rodrigues TO \& Medeiros MB. Avaliação das condições de trabalho, treinamento, saúde e segurança de brigadistas de combate a incêndios florestais em unidades de conservação do Distrito Federal: estudo de caso. Revista Árvore, 30(1): 55-63, $2006 \mathrm{~b}$.

Hessl A \& Spackman S. 1995. Effects of fire on threatened and endangered plants: an annotated bibliography. National Biological Service. 55p.

ICMBio. 2012 Plano de ação para ações de prevenção $e$ combate a incêndios florestais em unidades de conservação federais. Instituto Chico Mendes de Conservação da Biodiversidade. 20p.

IEF. 2006. Plano de Manejo Diretor do Parque Estadual do Grajaú. Fundação Instituto Estadual de Florestas. $112 \mathrm{p}$.

Koproski LP, Batista AC \& Soares RV. Ocorrências de incêndios florestais no Parque Nacional de Ilha Grande - Brasil. Floresta, 34(2): 193-197, 2004.

Kovalsyki B, Takashina IK, Tres A, Tetto AF \& Batista AC. Inflamabilidade de espécies arbóreas para uso em cortinas de segurança na prevenção de incêndios florestais. Pesquisa Florestal Brasileira, 36(88): 387-391, 2016.
Lima GS \& Soares RV. Avaliação da eficiência de combate aos incêndios florestais no Brasil. Floresta, 22(1/2): 25-38, 1992.

Lima GS, Torres FTP, Costa AG, Félix GA \& Silva-Júnior MR. Avaliação da eficiência de combate aos incêndios florestais em unidades de conservação brasileiras. Floresta, 48(1): 113-122, 2018.

Martinelli G, Martins E, Moraes M, Loyola R \& Amaro $\mathrm{R}$ (orgs.). 2018. Livro Vermelho da Flora Endêmica do Estado do Rio de Janeiro. Jardim Botânico do Rio de Janeiro, Secretaria de Estado do Ambiente. 456p.

Matos DMS, Santos CJF \& Chevalier DR. Fire and restoration of the largest urban forest of the world in Rio de Janeiro City, Brazil. Urban Ecosystems, 6(3): 151-161, 2002.

Medeiros MB \& Fiedler NC. Incêndios florestais no Parque Nacional da Serra da Canastra: desafios para a conservação da biodiversidade. Ciência Florestal, 14(2): 157-168, 2004.

Medeiros R, Young CEF, Pavese HB \& Araújo FFS (eds.). 2011. Contribuição das unidades de conservação brasileiras para a economia nacional: sumário executivo. UNEP-WCMC. 44p.

MMA (Ministério do Meio Ambiente). 2014. Portaria n. 443, de 17 de dezembro de 2014. Diário Oficial da União, Seção 1, 245, 18/12/2014: 110-121.

Oliveira RR, Zaú AS, Lima DF, Silva MBR, Vianna MC, Sodré DO \& Sampaio PD. 1995. Significado ecológico da orientação de encostas no Maciço da Tijuca, Rio de Janeiro, p. 523-541. In: Esteves FA (ed.). Oecologia Brasiliensis: estrutura, funcionamento e manejo de ecossistemas brasileiros. PPG Ecologia, UFRJ.

Ooi MKJ. The importance of fire season when managing threatened plant species: A long-term case-study of a rare Leucopogon species (Ericaceae). Journal of Environmental Management, 236: 17-24, 2016.

Penman TD, Collins L, Price OF, Bradstock RA, Metcalf $S$ \& Chong DM. Examining the relative effects of fire weather, suppression and fuel treatment on fire behavior - a simulation study. Journal of Environmental Management, 131: 325-333, 2013.

Penna-Firme R, Montezuma RCM, Santos RL \& Oliveira RR. 2004. Aspectos estruturais da paisagem da mata atlântica em áreas alteradas por incêndios florestais, p. 168-188. In: Oliveira RO (org.). As marcas do homem na floresta: história ambiental de um trecho urbano de mata atlântica. Ed. PUC-Rio.

Ramsey GS \& Higgins DG. 1981. Canadian forest fire statistics. In: Information report PI-X-9. Canadian Forestry Service. 71p. 
Ribeiro GA, Lima GS, Oliveira ALS, Camargos VL \& Magalhães MU. Eficiência de um retardante de longa duração na redução da propagação do fogo. Revista Árvore, 30(6): 1025-1031, 2006.

Rio de Janeiro. 2007. Termo de Sessão de Uso do Parque Estadual do Grajaú (processo E-14/144/2007). Diário Oficial do Estado do Rio de Janeiro, 09/01/2007: 20.

Santos JF, Soares RV \& Batista AC. Perfil dos incêndios florestais no Brasil em áreas protegidas no período de 1998 a 2002. Floresta, 36(1): 93-100, 2006.

Silva SAF. 1969. Contribuição ao estudo do "capim colonião" (Panicum maximum Jacq. var. maximum). II - Considerações sobre sua dispersão e seu controle. Vellozia, 7: 3-21.

Soares RV \& Batista AC. 2007. Incêndios florestais: controle, efeitos e uso do fogo. Universidade Federal do Paraná. 264p.
Soares RV \& Santos JF. Perfil dos incêndios florestais no Brasil de 1994 a 1997. Revista Floresta, 32(2): 219-232, 2002.

Tebaldi ALC, Fiedler NC, Juvanhol RS \& Dias HM. Ações de prevenção e combate aos incêndios florestais nas unidades de conservação estaduais do Espírito Santo. Floresta e Ambiente, 20(4): 538-549, 2013.

Torres FTP, Torres CMME, Lima GS, Martins SV, Mendes AEO, Padovani MT, Siqueira RG, Moreira GF $\&$ Valverde SR. Análise do perfil dos incêndios florestais no Parque Estadual da Serra do Brigadeiro e entorno (MG). Ciência Florestal, 28(3): 1008-1021, 2018.

Yates CJ \& Ladd PG. Using population viability analysis to predict the effect of fire on the extinction risk of an endangered shrub Verticordia fimbrilepis subsp. fimbrilepis in a fragmented landscape. Plant Ecology, 211(2), 305-319, 2010.

Zar JH. 1996. Biostatistical analysis. 3 ed. Prentice Hall. $662 \mathrm{p}$.

Biodiversidade Brasileira - BioBrasil.

Edição temática: Diálogos entre a Academia e a Gestão de Áreas Protegidas:

Programa de Pós-Graduação Profissional - Biodiversidade em Unidades de Conservação

n. 2, 2020

http://www.icmbio.gov.br/revistaeletronica/index.php/BioBR

Biodiversidade Brasileira é uma publicação eletrônica científica do Instituto Chico Mendes de

Conservação da Biodiversidade (ICMBio) que tem como objetivo fomentar a discussão e a disseminação de experiências em conservação e manejo, com foco em unidades de conservação $e$ espécies ameaçadas.

ISSN: 2236-2886 